Article

\title{
Dietary Fibres Differentially Impact on the Production of Phenolic Acids from Rutin in an In Vitro Fermentation Model of the Human Gut Microbiota
}

\author{
Jaroslav Havlik ${ }^{1}{ }^{\circledR}$, Vittoria Marinello ${ }^{1}$, Andrew Gardyne ${ }^{1}$, Min Hou ${ }^{1}$, William Mullen ${ }^{2}{ }^{\circledR}$, \\ Douglas J. Morrison ${ }^{3}(\mathbb{D})$, Thomas Preston ${ }^{3}(\mathbb{D})$, Emilie Combet ${ }^{1}$ (D) and Christine A. Edwards $1, *(\mathbb{D})$ \\ 1 Human Nutrition, School of Medicine, Dentistry and Nursing, College of Medical, Veterinary and Life \\ Sciences, University of Glasgow, Glasgow G31 2ER, UK; havlik@af.czu.cz (J.H.); \\ vittoria.marinello@lanarkshire.scot.nhs.uk (V.M.); andrew.gardyne@outlook.com (A.G.); \\ minhou@sjtu.edu.cn (M.H.); Emilie.CombetAspray@glasgow.ac.uk (E.C.) \\ 2 Institute of Cardiovascular and Medical Sciences, College of Medical, Veterinary and Life Sciences, \\ University of Glasgow, Glasgow G12 8QQ, UK; William.Mullen@glasgow.ac.uk \\ 3 Scottish Universities Environmental Research Centre, East Kilbride G75 0QF, UK; \\ Douglas.Morrison@glasgow.ac.uk (D.J.M.); Tom.Preston@glasgow.ac.uk (T.P.) \\ * Correspondence: Christine.Edwards@glasgow.ac.uk
}

Received: 21 April 2020; Accepted: 26 May 2020; Published: 28 May 2020

check for updates

\begin{abstract}
Polyphenols are often ingested alongside dietary fibres. They are both catabolised by, and may influence, the intestinal microbiota; yet, interactions between them and the impact on their resultant microbial products are poorly understood. Dietary fibres (inulin, pectin, psyllium, pyrodextrin, wheat bran, cellulose- three doses) were fermented in vitro with human faeces $(n=10)$ with and without rutin $(20 \mu \mathrm{g} / \mathrm{mL})$, a common dietary flavonol glycoside. Twenty-eight phenolic metabolites and short chain fatty acids (SCFA) were measured over $24 \mathrm{~h}$. Several phenolic metabolites were produced during fibre fermentation, without rutin. With rutin, 3,4-dihydroxyphenylacetic acid (3,4diOHPAA), 3-hydroxyphenylacetic acid (3OHPAA), 3-(3 hydroxyphenyl)propionic acid (3OHPPA) and 3-(3,4-dihydroxyphenyl)propionic acid (3,4diOHPPA; DOPAC) were produced, with 3,4diOHPAA the most abundant, confirmed by fermentation of ${ }^{13} \mathrm{C}$ labelled quercetin. The addition of inulin, wheat bran or pyrodextrin increased 3,4diOHPAA 22.5 -fold over $24 \mathrm{~h}(p<0.05)$. Rutin affected SCFA production, but this depended on fibre, fibre concentration and timepoint. With inulin, rutin increased $\mathrm{pH}$ at $6 \mathrm{~h}$ from 4.9 to $5.6(p=0.01)$ but increased propionic, butyric and isovaleric acid $(1.9,1.6$ and 5 -fold, $p<0.05$ at $24 \mathrm{~h}$ ). Interactions between fibre and phenolics modify production of phenolic acids and SCFA and may be key in enhancing health benefits.
\end{abstract}

Keywords: colonic metabolism; flavonols; gas chromatography mass spectrometry; gut microbiome; phenolic acids; dietary fibre

\section{Introduction}

Intake of plant phenolics is estimated to be $\sim 1$ g per day [1-3] in most populations, a small proportion of which are flavonols [3,4]. Daily flavonol intake varies between populations and dietary intake patterns: from 5.4 mg per day in Finland [5], $19 \mathrm{mg}$ per day Spain [6] and $34 \mathrm{mg}$ per day in France [1], with $59 \%-79 \%$ of daily flavonol intake represented by quercetin glycosides [1,6]. Rutin is an abundant glycosidic form of quercetin, found in significant quantities in capers, black olives and buckwheat (332, 45 and $36 \mathrm{mg} / 100 \mathrm{~g}$ fresh food weight, respectively) [7]. Drupe fruits such as blackcurrants and raspberries may also provide up to $11 \mathrm{mg}$ of rutin per $100 \mathrm{~g}[7,8]$. Research on 
flavonols as plant food bioactives with proposed health benefits has expanded in the last two decades, with major focus on cancers and cardiovascular diseases [9-12].

The metabolism of rutin has been extensively studied ex vivo [13-15], in rodents [16-18] and in human intervention studies: after ingestion, only $14 \%-17 \%$ of rutin is absorbed in the small intestine $[19,20]$. Most ingested rutin therefore enters the colon, where it is catabolised by the gut microbiota via a pathway starting with the hydrolytic cleavage of the disaccharide moiety [19-21]. This, combined with fission of the C-ring of the aglycone, results in the formation of a series of phenolic acids and phloroglucinol derivatives from either of the two remaining rings [15]. There is a high degree of inter-individual variability in the metabolites produced [15,21], with age [21] and ethnicity [22], two factors shown to modify the metabolite fingerprint excreted in urine. Although 3,4diOHPAA is usually the dominant early metabolite, some individuals appear to shift metabolism towards different phenolic products [15]. Phenolic acids are absorbed from the colon and released into the circulation alongside other metabolites and are therefore speculated to be responsible for some of the biological effects of rutin $[15,23]$. The main metabolite, 3,4diOHPAA, has been shown to possess high biological activities in vitro with some advantages over its parent compound, such as low toxicity and solubility [24], antiplatelet aggregation properties [25], suppression of lipopolysaccharide induced pro-inflammatory cytokines TNF- $\alpha$, IL-1 $\beta$ and IL-6 in peripheral blood mononuclear cells [26] and inhibition of protein glycation $[23,27]$.

Much of the evidence for gut-microbiota-mediated metabolism of polyphenols to date has been assessed using in vitro batch cultures with human stool samples. The studies differ in media used. Some cultures did not contain any fermentable carbohydrates $[13,15,28,29]$, while others did [14,30]. The presence of fermentable carbohydrates in media, however, might be an important factor changing the pattern of polyphenol catabolism, yet the results are contrasting. More rapid fermentation of rutin was seen in the presence of glucose [15] resulting in greater production of metabolites, while less total phenolic acids and 3,4diOHPAA were seen in the presence of complex carbohydrates in the medium [31]. There are several potential mechanisms by which additional fermentable carbohydrate impacts upon bacterial polyphenol catabolism. Firstly, fermentation of carbohydrates to short chain fatty acids (SCFA) results in a decrease in colonic $\mathrm{pH}$ [32] promoting changes in bacterial enzyme activity [33]. Secondly, some fibres may be selective in promoting growth of specific bacterial groups within the intestinal microbiota [34], thus altering polyphenol metabolism. Thirdly, dietary fibres could decrease or delay colonic polyphenol availability by altering small intestinal absorption and transit time [35]. Finally, dietary fibre may be a rich source of non-extractable polyphenols and release associated metabolites when they are fermented by the bacteria [36], which trigger antimicrobial action or inhibit bacterial hydrolases.

The evidence suggests that the polyphenol metabolites produced by the gut microbiota change (in terms of quality and quantity) in the presence of fibre. In this study, we undertook a systematic investigation of the impact of dietary fibres (pectin, inulin, psyllium, pyrodextrin, wheat bran and cellulose) on the catabolism of rutin in human faecal batch cultures, to inform food product formulation (e.g., soups, juices), towards improved products with higher health impact.

\section{Materials and Methods}

\subsection{Chemicals}

Oxygen free nitrogen (OFN) was from BOC-Linde (UK). Chemicals used as standards (Supplementary materials, Table S1), 3-(3-hydroxyphenyl)propionic acid [3,3OHPPA], 3-3,4-dihydroxyphenyl)propionic acid [3,3,4diOHPPA], 4-hydroxy 3-methoxyphenylacetic acid [4OH3MPAA] and 4-hydroxymandelic acid [4OH-mandelic acid] were from Alfa Aesar (Thermo Fisher Scientific, MA, USA), 2,4,5trimethoxycinnamic acid [TMCA], 3-(3-hydroxy 4-methoxyphenyl)propionic acid [3,3OH4MPPA], 3-(4-hydroxy 3-methoxyphenyl)propionic acid [3,4OH3MPPA], 3-(4-hydroxyphenyl)propionic acid [3,4OHPPA], 3,4-dihydroxybenzoic acid [3,4OHBA], 3,4-dihydroxyphenylacetic acid [3,4DiOHPAA], 
3-hydroxy-4-methoxycinnamic acid [isoferulic acid], 3-hydroxy-4-methoxyphenylacetic acid [3OH4MPAA], 3-hydroxybenzoic acid [3OHBA], 3-hydroxyphenylacetic acid [3OHPAA], phenylacetic acid [PAA], 3-phenyllactic [3PLA], 3-phenylpropionic acid [3PPA], 4-hydroxy 3-methoxybenzoic acid [VAN], 4-hydroxybenzoic acid [4OHBA], 4-hydroxyphenyl acetic acid [4OHPAA], benzoic acid [BA], caffeic acid, ferulic acid, mandelic acid, $p$-coumaric acid, phloroglucinol, pyrocatechol, quercetin, resorcinol and trans-cinnamic acid were purchased from Sigma Aldrich. The uniformly labelled ${ }^{13} \mathrm{C}$ quercetin ( $>98.5 \% \mathrm{C}$ atom labelled) was obtained from Isolife (NL). The fibres used in the study were as follows: inulin HP ([INU]; Beneo-Orafti, BE), pectin [PEC] from citrus peel and $\alpha$-cellulose ([CEL]; Sigma Aldrich), wheat bran Organic ([WB]; Infinity Foods, UK), powdered psyllium husks ([ISP]; Myprotein, UK), pyrodextrin or else resistant maltodextrin [RM] was Fibersol-2 (Matsutani Chemical Industry, JP). Other solvents, buffer constituents, and reagents were from Sigma-Aldrich and were of highest available purity.

\subsection{In Vitro Fermentation Model}

\subsubsection{Donors, Sampling and Faecal Slurry Preparation}

Faecal samples were obtained from healthy donors aged 20 to 41 years (mean age 27), with a mean BMI $26.3 \mathrm{~kg} / \mathrm{m}^{2}$ (ranging 22.8-35.1). Donors were mostly male (72\%), all Caucasian, had not undergone antibiotic treatment in the previous 6 months, had no history of gastrointestinal disease, and were not vegetarian or vegan. All subjects followed a low polyphenol-low fibre diet (for details, see Supplementary Materials, Figure S3) for $48 \mathrm{~h}$ before providing a faecal sample. The study was approved by the College of Medical, Veterinary and Life Sciences Ethics Committee, University of Glasgow (no. 2011023) and donors gave written informed consent.

Stool samples were collected using in-house collection kits consisting of a sealed $0.7 \mathrm{~L}$ plastic container sealed within a plastic bag with the addition AnaeroGen ${ }^{\mathrm{TM}} 3.5 \mathrm{~L}$ Sachet (Oxoid, UK) after sample collection. The samples were processed in the laboratory within $2 \mathrm{~h}$ of sampling. A faecal slurry $(25 \% \mathrm{wt} / \mathrm{wt})$ was prepared by mixing $50 \mathrm{~g}$ of faeces with $150 \mathrm{~mL}$ of sterile OFN-purged phosphate buffer, $\mathrm{pH} 7.0$ using a blender and the particulate material was removed by straining through nylon mesh.

\subsubsection{Fibres}

Fibres were pre-weighed (0.8, 1.7 and $3.3 \mathrm{~g}$ ) into $100 \mathrm{~mL}$ gas-tight, crimp-top sealed fermentation bottles, to represent assay concentrations corresponding to a physiologically representative bolus intake of 5, 10 and $20 \mathrm{~g}$ of fibre potentially diluted in $300 \mathrm{~mL}$ of colonic contents [37]. INU, WB, $\mathrm{RM}$ and CEL were tested at all three concentrations. Only fermentations containing 0.8 and $1.7 \mathrm{~g}$ fibre were used for PEC and just $0.8 \mathrm{~g}$ for ISP due to the high viscosity. Vials containing no fibre were also included (no fibre blanks). The fermentations were carried out with and without rutin to account for any phenolics intrinsically present in the fibres.

\subsubsection{Faecal Incubations}

Each vial contained $42 \mathrm{~mL}$ of fermentation medium at $\mathrm{pH} 7.0,2 \mathrm{~mL}$ of reducing solution and $1 \mathrm{~mL}$ of rutin aqueous solution $(1 \mathrm{mg} / \mathrm{mL})$ or water for blanks [38]. In some cases, the size of the fermentation model was scaled-down by half due to low donor faecal sample weight. The rutin concentration used in the fermentations in this study was selected based on $86 \%$ rutin recovery in ileostomy subjects [19] assuming a postprandial ileal output of $162 \mathrm{~mL}$ within $2 \mathrm{~h}$ after consuming a $300 \mathrm{~mL}$ meal [39] and additional estimated two-fold dilution in the proximal colon by colonic secretions. Under these conditions, a moderate intake of fruit, e.g., $200 \mathrm{~g}$ of blackberries containing $3.89 \mathrm{mg} / 100 \mathrm{~g}$ [8] may result in approximately $20 \mu \mathrm{g} / \mathrm{mL}$ of rutin in the proximal colon.

After full decolouration of the medium, we inoculated with $5 \mathrm{~mL}$ of faecal slurry (total volume $50 \mathrm{~mL}$ ) and incubated in a shaking bath at $37^{\circ} \mathrm{C}, 60$ strokes/min and sampled at $0 \mathrm{~h}, 6 \mathrm{~h}$ and $24 \mathrm{~h}$. Aliquots $(5 \times 1 \mathrm{~mL})$ were collected with a syringe and needle through the self-sealing septa at each 
timepoint and stored at $-80^{\circ} \mathrm{C}$. One aliquot was used for $\mathrm{pH}$ determination with a calibrated $\mathrm{pH}$ meter (Hannah pH20 instruments, USA). Aliquots for SCFA analysis were alkalized to $\mathrm{pH}>9$ prior to storage $[38,40]$.

\subsection{4. ${ }^{13} \mathrm{C}$ Labelled Quercetin Study}

${ }^{13} \mathrm{C}$ quercetin $(10 \mu \mathrm{g} / \mathrm{mL})$ was fermented in parallel with native quercetin $\left({ }^{12} \mathrm{C}\right)$ and corresponding controls. No fibre was added. The experiment was carried out as two independent replicates with the stool of a single donor donated within 1 month. The conditions were the same as above apart from being scaled-down to $1.5 \mathrm{~mL}$ of the fermentation fluid in each of the $5 \mathrm{~mL}$ vials. Quercetin $(5 \mathrm{mg} / \mathrm{mL}$, $3 \mu \mathrm{L}$ in $100 \%$ methanol, $10 \mu \mathrm{g} / \mathrm{mL}$ in the assay) was injected into the incubation vials with a glass syringe. At each timepoint $(0 \mathrm{~h}, 3 \mathrm{~h}, 6 \mathrm{~h}$ and $24 \mathrm{~h})$, vials were taken and frozen at $-80{ }^{\circ} \mathrm{C}$. Blank cultures not containing quercetin and samples containing quercetin but not stool inoculum (labelled as INI for timepoint $0 \mathrm{~h}$ ) were prepared in parallel. They were thawed just before extraction and spun at $6000 \times g$ to remove particulate material from the supernatant.

\subsection{Fibre-Phenolic Sequestration Experiment}

To investigate the effect of fibres on recovery of phenolics from fermentation samples, fibres were pre-weighed in $5 \mathrm{~mL}$ tubes in amounts of 8,17 and $33 \mu \mathrm{g}$ and subsequently hydrated with $500 \mu \mathrm{L}$ of distilled water ( $\mathrm{pH} 5.5$ ), so that the final concentration corresponded to equivalent of $0.8,1.7$ and $3.3 \mathrm{~g} / 50 \mathrm{~mL}$ After spiking with mixed standards, $\left(5 \mu \mathrm{g}\right.$ each), solutions were incubated for $6 \mathrm{~h}$ at $37^{\circ} \mathrm{C}$ and extracted using the same procedure as for fermentation samples.

\subsection{Phenolic Acids Extraction}

A gas chromatography-mass spectrometry (GC/MS) analysis of phenolic compounds in fermentation fluid was performed as previously described [41] with modifications. Fermentation aliquots were thawed and volumes of $500 \mu \mathrm{L}$ transferred to $5 \mathrm{~mL}$ glass tubes. Internal standard solution (ISTD; $30 \mu \mathrm{L}$ of $0.2 \mathrm{mg} / \mathrm{mL}$ 2,4,5-trimethoxycinnamic acid) was added, the mixture vortexed, acidified with $60 \mu \mathrm{L}$ of $1 \mathrm{M} \mathrm{HCl}$, vortexed again, and left at $4{ }^{\circ} \mathrm{C}$ for $10 \mathrm{~min}$. The mixture was then extracted twice with $1.5 \mathrm{~mL}$ of ethyl acetate. After each extraction step, the upper organic layer was removed after centrifugation at $1600 \times g$ and transferred to $1.5 \mathrm{~mL}$ amber vials. Samples were evaporated at $45^{\circ} \mathrm{C}$ until dryness (approx. $40 \mathrm{~min}$ ) on Savant SpeedVac SPD131DDA concentrator (Thermo Fisher Scientific, MA, USA), with repetitive extractions being pooled in the same corresponding vial. After the second evaporation, vial walls were rinsed with $200 \mu \mathrm{L}$ of dichloromethane and evaporated again for $10 \mathrm{~min}$. Dry residues were derivatised under OFN, using $50 \mu \mathrm{L}$ of $\mathrm{N}, \mathrm{O}-\mathrm{Bis}$ (trimethylsilyl)trifluoroacetamide (BSTFA) with $1 \%$ chlorotrimethylsilane (TMCS) for $4 \mathrm{~h}$ at $65^{\circ} \mathrm{C}$.

\subsection{Phenolic Acid Analysis}

Anhydrous hexane $(99 \%, 400 \mu \mathrm{L})$ was added to each vial before analysis. A set of 13 calibration solutions, containing 28 phenolic acids, hydroxybenzenes and quercetin ranging from $1 \mu \mathrm{g}$ to $80 \mu \mathrm{g} / \mathrm{mL}$, was extracted and analysed alongside all faecal samples. The analysis was performed on a Trace GC equipped with a split/splitless injector interfaced to a DSQ mass spectrometer and an AI3000 autosampler (Thermo Fisher Scientific, MA, USA) using the following conditions: inlet temperature $250{ }^{\circ} \mathrm{C}$, split injection (1:25), $1 \mu \mathrm{L}$ sample volume. A Zebron ${ }^{\mathrm{TM}} \mathrm{ZB}-5$ capillary column $(30 \mathrm{~m} \times 0.25 \mathrm{~mm}$ i.d., $\mathrm{df}=0.25 \mu \mathrm{m})$ was used for separation. The carrier gas flow $(\mathrm{He})$ was constant at $1.2 \mathrm{~mL} / \mathrm{min}$. The oven programme started at $140{ }^{\circ} \mathrm{C}$ (held $0.5 \mathrm{~min}$ ), rose to $160^{\circ} \mathrm{C}$ at $6{ }^{\circ} \mathrm{C} / \mathrm{min}$ to $270{ }^{\circ} \mathrm{C}$ and was increased then at $30^{\circ} \mathrm{C} / \mathrm{min}$ to a final temperature of $320^{\circ} \mathrm{C}$ (held for $4 \mathrm{~min}$ ). The transfer line was maintained at $310{ }^{\circ} \mathrm{C}$ and ion source temperature at $270{ }^{\circ} \mathrm{C}$. Acquisition was performed in positive electron ionization mode in full scan $(\mathrm{m} / \mathrm{z} 50-450)$ with an ionization energy of $70 \mathrm{eV}$, from 1.7 to $20 \mathrm{~min}$. Quercetin and ${ }^{13} \mathrm{C}$-quercetin were monitored using single ion monitoring (SIM) for ion $\mathrm{m} / \mathrm{z} 647$, 
662 and 595 respectively, from 21-25 min. Identification of phenolics and quercetin was achieved by comparison with the retention times and mass spectra of authentic standards. Acquisition and analyses of GC-MS data were performed on Xcalibur version 2.1 (Thermo Fisher Scientific, MA, USA). The ${ }^{13} \mathrm{C}$-quercetin and its products were quantified using calibration curves based on quantifier ions of the corresponding non-labelled compounds in MS Excel. Differences between controls and treatments were thoroughly checked for unknown metabolites using AMDIS ver. 2.1, Compare Files Postanalysis feature. A detailed GC-MS method including conditions and basic validation is shown in Supplementary Materials, Table S2.

\subsection{Short Chain Fatty Acid Extraction and Analysis}

Short chain fatty acids (SCFA) were measured by GC-FID of acidified ether extracts of the fermentation fluid as previously described [31].

\subsection{Statistical Analysis}

Data were expressed as mean values and visualised in IBM SPSS Statistics ver. 22 (International Business Machines, NY, USA). Normality was assessed using the Shapiro-Wilk test. Due to non-normal distribution in some subsets, skewness was reduced by log10 transformation. Potential differences between controls and treatments were analysed using 3-way repeated measures analysis of covariance (MANOVA), one-way ANOVA with Dunnett's or Tukey's post hoc test for factors fibre (INU, PEC, ISP, $\mathrm{RM}, \mathrm{WB}, \mathrm{CEL})$, concentration $(0,0.8,3.3 \mathrm{~g} / 50 \mathrm{~mL}$ of fibre), rutin (including rutin, $\mathrm{R}+$; excluding rutin $\mathrm{R}-$ ) or Time ( $0 \mathrm{~h}, 6 \mathrm{~h}, 24 \mathrm{~h})$ on the 28 phenolic metabolites used as variables as indicated in the method section.

Areas under $24 \mathrm{~h}$ curve $\left(\mathrm{AUC}_{24}\right)$ were established for compounds of interest, reflecting their total production in solution. If the solution initially contains $10 \mu \mathrm{g} / \mathrm{mL}$ of a compound which remains unmetabolised over time, the $\mathrm{AUC}_{24}$ value will be $240 \mu \mathrm{g} / \mathrm{mL} / 24 \mathrm{~h}$; analogously, if same compound is linearly metabolised to 0 within $24 \mathrm{~h}$, it produces an $\mathrm{AUC}_{24}$ of $120 \mu \mathrm{g} / \mathrm{mL} / 24 \mathrm{~h}$.

The effects of rutin on SCFA and $\mathrm{pH}$ were analysed using independent samples t-test (2-tailed) for each factor with a Benjamini-Hochberg multiple testing correction. No data transformation was applied. Levene's test was used to assess equality of variances. Results were expressed as means \pm S.E.M or S.D. and were considered significant at $p<0.05$.

\section{Results}

\subsection{GC-MS Method Optimisation and Validation}

The method was adapted from [42] and internally validated. Recoveries were determined by spiking a pooled faecal sample with phenolic acid standards at concentrations of $10 \mu \mathrm{g} / \mathrm{mL}$. Average recoveries were $91 \%$, typically ranging between $81 \%$ and $106 \%$, however, for $4 \mathrm{OH}$-mandelic acid, BA, 3PPA, PAA and the polar hydroxybenzenes, such as resorcinol or phloroglucinol recoveries were low $(10 \%-26 \%)$. Limits of detection (signal-to-noise ratio of 3:1) for four main rutin metabolites: 3OHPAA, 3,3OHPPA, 3,4diOHPAA and 3,3,4diOHPPA were $0.2,0.15,0.08$ and $0.25 \mu \mathrm{g} / \mathrm{mL}$, respectively. Basic method validation data are shown in Supplementary Materials, Table S2.

\subsection{Phenolics and Their Metabolites Released from Fibres}

Fibres alone, even without addition of rutin released significant amounts of phenolics, which showed fibre-specific patterns (Figure 1, Table 1). 


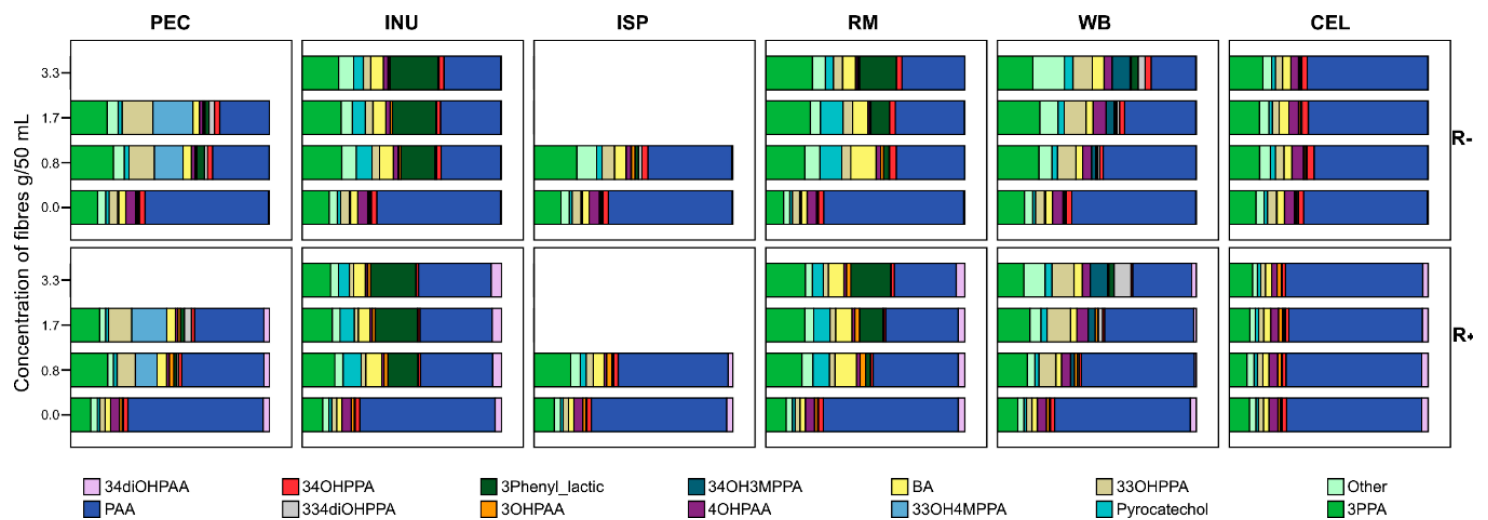

Figure 1. Relative profile of phenolic metabolites ( $\left.\mathrm{rel}_{\mathrm{H}} \mathrm{AUC}_{24}\right)$ released from fibres present in the medium in fermentation vials with rutin added $(\mathrm{R}+, 20 \mu \mathrm{g} / \mathrm{mL})$ and without rutin (R-); INU, inulin, PEC, pectin, ISP, psyllium, RM, pyrodextrin, WB, wheat bran, CEL, cellulose; $n=10$. The light pink bar refers to the main metabolite of rutin and shows its rather low proportion in the whole pool of phenolic acid metabolites present. For other abbreviations, see Materials and Methods section.

Table 1. Area under the curve $\left(\mathrm{AUC}_{24}\right)$ of phenolics found in fermentation slurries with fibres only (rutin not added) at $0.8 \mathrm{~g} / 50 \mathrm{~mL}, \mathrm{AUC}_{24} \mu \mathrm{g} / \mathrm{mL} / 24 \mathrm{~h}$.

\begin{tabular}{|c|c|c|c|c|c|c|c|}
\hline & \multicolumn{7}{|c|}{ Fibre } \\
\hline & PEC & INU & ISP & RM $\#$ & WB & CEL & Blank \#\# \\
\hline & Mean \pm SEM & Mean \pm SEM & Mean \pm SEM & Mean \pm SEM & Mean \pm SEM & Mean \pm SEM & Mean \pm SEM \\
\hline $\mathrm{BA}$ & $37.1 \pm 4.4$ & $49.7 \pm 6.6$ & $37.7 \pm 5.3^{*}$ & $78.4 \pm 15.7$ & $48.0 \pm 4.6$ & $35.1 \pm 6.1$ & $33.3 \pm 3.7$ \\
\hline PAA & $245.6 \pm 20.9^{* *}$ & $205.1 \pm 15.4 * *$ & $267.3 \pm 19.1^{* *}$ & $233.2 \pm 16.7^{* *}$ & $649.4 \pm 53.6$ & $510.7 \pm 37.8$ & $598.5 \pm 40.9$ \\
\hline Pyrocatechol & $20.6 \pm 4.5$ & $58.7 \pm 8.6^{*}$ & $16.8 \pm 3.2$ & $43.3 \pm 2.9^{* *}$ & $38.3 \pm 5.4^{* *}$ & $23.4 \pm 5.2$ & $15.3 \pm 3.8$ \\
\hline Resorcinol & $8.0 \pm 2.7$ & $6.2 \pm 2.5$ & $7.2 \pm 2.6$ & $0.0 \pm 0.0$ & $9.2 \pm 2.6$ & $6.4 \pm 2.2$ & $5.1 \pm 1.8$ \\
\hline 3РPA & $191.6 \pm 21.6$ & $139.6 \pm 16.5$ & $136.3 \pm 11.8$ & $129.3 \pm 5.0$ & $280.6 \pm 32.8$ & $139.6 \pm 16.6$ & $118.3 \pm 12.4$ \\
\hline Mandelic acid & $5.3 \pm 1.4$ & $4.4 \pm 1.2$ & $10.3 \pm 1.8^{* *}$ & $1.4 \pm 0.6$ & $10.4 \pm 1.8^{*}$ & $3.1 \pm 0.8$ & $2.5 \pm 0.6$ \\
\hline Cinnamic acid & $4.6 \pm 1.7^{*}$ & $2.8 \pm 1.4$ & $2.2 \pm 1.3$ & $0.0 \pm 0.0$ & $2.3 \pm 1.2$ & $1.8 \pm 1.0$ & $1.9 \pm 1.0$ \\
\hline 3НBA & $3.2 \pm 1.5^{*}$ & $6.6 \pm 3.3$ & $6.3 \pm 3.0$ & $10.7 \pm 2.3$ & $5.9 \pm 3.0$ & $3.7 \pm 1.6$ & $3.9 \pm 2.0$ \\
\hline 3-Phenyllactic acid & $34.5 \pm 6.6$ & $120.6 \pm 15.5^{* *}$ & $11.9 \pm 5.1$ & $22.1 \pm 9.9$ & $7.2 \pm 1.7$ & $2.4 \pm 0.6$ & $4.6 \pm 1.5$ \\
\hline 3ОНРАA & $7.0 \pm 1.2$ & $7.1 \pm 1.3$ & $10.7 \pm 1.4$ & $8.9 \pm 2.4$ & $7.6 \pm 1.2$ & $6.7 \pm 1.2$ & $4.5 \pm 0.8$ \\
\hline 4OHBA & $3.7 \pm 0.6$ & $4.9 \pm 1.0$ & $6.8 \pm 0.8$ & $10.4 \pm 1.8^{*}$ & $12.8 \pm 1.1^{* *}$ & $6.1 \pm 1.2$ & $2.8 \pm 0.6$ \\
\hline Phloroglucinol & $3.8 \pm 1.3$ & $10.9 \pm 3.1$ & $7.3 \pm 2.0$ & $6.4 \pm 2.8$ & $7.1 \pm 2.1$ & $6.4 \pm 2.1$ & $7.9 \pm 1.8$ \\
\hline 4OHPAA & $14.1 \pm 1.4^{* *}$ & $16.8 \pm 2.3^{* *}$ & $12.4 \pm 1.5^{* *}$ & $14.3 \pm 3.1^{* *}$ & $62.4 \pm 4.1$ & $52.2 \pm 3.7$ & $50.0 \pm 4.0$ \\
\hline 3,3ОНРPA & $115.3 \pm 8.5^{* *}$ & $26.2 \pm 3.9^{* *}$ & $37.3 \pm 4.7$ & $11.6 \pm 3.4^{* *}$ & $128.5 \pm 17.7^{* *}$ & $36.3 \pm 4.3$ & $40.9 \pm 6.8$ \\
\hline VAN + iso-VAN & $0.9 \pm 0.3$ & $1.2 \pm 0.3$ & $3.1 \pm 0.6$ & $2.4 \pm 1.0$ & $7.3 \pm 0.7^{*}$ & $1.2 \pm 0.3$ & $0.8 \pm 0.2$ \\
\hline 4-OHmandelic acid & $2.6 \pm 1.2$ & $2.9 \pm 1.1$ & $1.6 \pm 0.7$ & $0.0 \pm 0.0$ & $1.8 \pm 0.7$ & $3.2 \pm 1.0$ & $0.6 \pm 0.1$ \\
\hline $\begin{array}{c}\text { 3OH4MPAA + } \\
\text { 4OH3MPAA }\end{array}$ & $7.2 \pm 2.3$ & $5.2 \pm 1.5$ & $7.1 \pm 2.6$ & $15.5 \pm 6.9$ & $11.1 \pm 2.9$ & $11.6 \pm 4.3$ & $6.1 \pm 2.6$ \\
\hline 3,4OHPPA & $23.2 \pm 3.4$ & $16.9 \pm 3.5$ & $18.5 \pm 3.6$ & $14.1 \pm 4.8$ & $26.0 \pm 3.7$ & $32.3 \pm 5.9$ & $27.6 \pm 5.5$ \\
\hline 3,4diOHBA & $1.0 \pm 0.2$ & $2.3 \pm 0.4$ & $1.5 \pm 0.2$ & $3.3 \pm 0.5^{* *}$ & $5.3 \pm 0.5^{* *}$ & $1.0 \pm 0.3$ & $3.1 \pm 1.5$ \\
\hline 3,4diOHPAA & $2.5 \pm 0.5$ & $1.3 \pm 0.4$ & $4.3 \pm 0.6$ ** & $0.4 \pm 0.2$ & $2.8 \pm 0.5$ & $1.2 \pm 0.3$ & $4.0 \pm 1.0$ \\
\hline 3,3ОН4MPPA & $132.5 \pm 12.0^{* *}$ & $0.5 \pm 0.1^{* *}$ & $0.6 \pm 0.2$ & $0.0 \pm 0.0$ & $0.4 \pm 0.2$ & $0.4 \pm 0.2$ & $5.0 \pm 2.1$ \\
\hline 3,4OH3MPРA & $2.1 \pm 0.6$ & $1.5 \pm 0.6$ & $1.8 \pm 0.9^{* *}$ & $0.0 \pm 0.0 * *$ & $26.3 \pm 3.2^{* *}$ & $2.1 \pm 0.6$ & $1.0 \pm 0.4$ \\
\hline 3,3,4diOHPPA & $12.2 \pm 3.7$ & $4.0 \pm 2.0$ & $8.9 \pm 2.6$ & $2.2 \pm 1.0$ & $9.6 \pm 1.6^{* *}$ & $6.2 \pm 2.3$ & $5.8 \pm 1.8$ \\
\hline$p$-Coumaric acid & $0.2 \pm 0.1$ & $0.3 \pm 0.1$ & $0.4 \pm 0.1$ & $0.0 \pm 0.0$ & $0.5 \pm 0.1$ & $0.1 \pm 0.0$ & $0.4 \pm 0.1$ \\
\hline 3OH4M Cinnamic acid & $0.5 \pm 0.3$ & $0.1 \pm 0.1$ & $0.4 \pm 0.1$ & $0.0 \pm 0.0$ & $0.5 \pm 0.2$ & $0.0 \pm 0.0$ & $0.1 \pm 0.1$ \\
\hline Ferulic acid & $0.2 \pm 0.1$ & $0.2 \pm 0.1$ & $0.6 \pm 0.2$ & $0.0 \pm 0.0$ & $5.2 \pm 0.7^{* *}$ & $0.4 \pm 0.1$ & $0.6 \pm 0.2$ \\
\hline Caffeic acid & $4.6 \pm 2.0$ & $4.2 \pm 2.1$ & $5.7 \pm 1.9$ & $0.8 \pm 0.4$ & $3.6 \pm 1.0$ & $2.9 \pm 1.0$ & $2.7 \pm 1.3$ \\
\hline Quercetin & $6.0 \pm 3.3$ & $7.0 \pm 3.8$ & $11.7 \pm 2.9^{* *}$ & $0.0 \pm 0.0$ & $7.8 \pm 3.2$ & $3.0 \pm 1.6$ & $4.4 \pm 1.8$ \\
\hline
\end{tabular}

* significantly different at $p<0.05$ from CEL; ** significantly different at $p<0.01$ from CEL using multivariate ANOVA with Dunnett's post hoc test; $n=10$ except $\left(^{\#}, n=2, \#, n=17\right)$; S.E.M, standard error of mean; values in bold refer to a significant increase of the analyte in comparison to the blank; INU, inulin, PEC, pectin, ISP, psyllium, $\mathrm{RM}$, pyrodextrin, WB, wheat bran, CEL, cellulose.

Some of these (pyrocatechol; BA; PAA; 3PPA; 3,3OHPPA; 3,3,4diOHPPA or 3,3OH4MPPA) are potential rutin catabolites. In fermentations blank or CEL (no matter if rutin was present or not), phenolic profile was similarly represented by high $\mathrm{AUC}_{24}$ for PAA $(510-600 \mu \mathrm{g} / \mathrm{mL} / 24 \mathrm{~h})$ and 3PPA $(118-140 \mu \mathrm{g} / \mathrm{mL} / 24 \mathrm{~h}$ ) (Figure 1, Table 1). The presence of fermentable carbohydrates except WB decreased PAA 2-fold, and increased selected phenolics in fibre-specific manner, e.g., 3PLA was highest in fermentations of INU and 3,3OHPPA and 3,3H4MPPA were more abundant when PEC 
was fermented. None of the fibres released 3,4diOHPAA-(the main rutin metabolite) in significant quantities except ISP which contained also very small significant amounts of quercetin (Table 1).

\subsection{Fibre-Phenolics Sequestration Interactions}

When spiking the fibre suspensions in aqueous solution ( $\mathrm{pH} 5.0$ ) with $5 \mu \mathrm{g}$ of standards, we observed $\sim 160 \%$ recoveries for all metabolites in the presence of PEC, as a consequence of ISTD sequestration. Recoveries of the four potential rutin metabolites (3OHPPA, 3,4diOHPAA, 3,3,4diOHPPA) except 3,3OHPAA, were significantly lower in the presence of WB than that of BLA. WB also highly reduced the recovery of non-rutin metabolites mandelic acid, caffeic acid, $p$-coumaric acid but more importantly that of quercetin and moderately that of 4OHPAA, both potential rutin metabolites (for details, see Supplementary Materials, Table S3). At the highest concentration of $\mathrm{WB}$, the majority of these compounds were trapped in the matrix, resulting in poor $<4 \%$ recoveries. The most prominent effect of WB was seen on 3,4diOHPAA and quercetin, even the lowest concentration present in the sample reduced their recoveries to 8 and 13\%, respectively. However, other fibres did not interfere with the recovery of the spiked standards and these were $98 \%-107 \%$ compared to recoveries from blank samples (Supplementary Materials, Table S3).

\subsection{Colonic Catabolism of Rutin in a Human Batch Fermentation Model}

When no fibre was present in fermentations, rutin was catabolised to a limited set of products: quercetin, 3,4diOHPAA, 3OHPAA, 3,3OHPPA and traces of 3,3,4diOHPPA. The sum of the metabolites explained $52 \%, 23 \%$ and $21 \%$ of the original molecular mass of the quercetin aglycone at 0,6 and $24 \mathrm{~h}$, respectively. Some of the catabolites were also found in incubations without rutin. The data are shown in Figure 2A. To reveal the origin of these, the isotope-labelled experiment with ${ }^{13} \mathrm{C}$-quercetin was conducted and has shown, that approximately $40 \%$ of the phenolic acids observed in fermentations do not originate from the added compound but are formed from other substrates. While $100 \%$ of $3,4 \mathrm{diOHPAA}$ was carrying the label, $75 \%$ of $3 \mathrm{OHPAA}$ was labelled alongside $25 \%$ unlabelled at both timepoints. Of the 3,3OHPPA only $17 \%-25 \%$ of the metabolite found was labelled alongside the majority of unlabelled compound (Figure $2 \mathrm{~B}$ ). Only a small proportion $(0.1 \%)$ of labelled 3,3,4diOHPPA was found alongside the omnipresent unlabelled 3,3,4diOHPPA (not shown in the graph). Most of the 3,3OHPPA but also a large proportion of 3OHPAA are thus formed from precursors present in medium. The mean sum of ${ }^{13} \mathrm{C}$ products for all fermentation timepoints was $5.38,3.79$ and $5.57 \mu \mathrm{g} / \mathrm{mL}$ of the $10 \mu \mathrm{g} / \mathrm{mL}$ added at $3 \mathrm{~h}, 6 \mathrm{~h}$ and $24 \mathrm{~h}$, respectively. No other ${ }^{13} \mathrm{C}$ products were found.

\subsection{Effects of Fibres on Rutin Metabolites}

Despite the previous observations that rutin formed only a limited set of metabolites in fermentations without fibres, we investigated its effect on the whole profile of phenolic acids using a three-way MANOVA with fibre, concentration and rutin addition as factors. The between-subjects effects indicated a significant effect $(p<0.05)$ on six phenolic metabolites: mandelic acid, $\mathrm{F}(12,1174)=2.7$, $p=0.001$, vanillic + iso-vanillic acid, $\mathrm{F}(12,1174)=3.258, p=0.001 ; 3,4$ diOHPAA, $\mathrm{F}(12,1174)=2.22$, $p=0.009 ; 3,3,4 \mathrm{diOHPPA} \mathrm{F}(12,1174)=2.01, p=0.020$ and $p$-coumaric acid, $\mathrm{F}(12,1174)=4.529, p=0.001$. The significant interaction for 3,4diOHPAA was investigated by simpler interaction analysis using independent samples t-test (2-tailed) between no fibre added and each fibre concentrations, separately for each timepoint.

WB significantly increased the concentration of 3,4diOHPAA at $24 \mathrm{~h}, p=0.006$ compared to no fibre, with an 2.3-fold increase between blank and the highest concentration tested and INU presence at $24 \mathrm{~h}$ facilitated a 2.5-fold increase between blank and the highest concentration $p=0.018$ and a 2.3-fold increase for the concentration $1.7 \mathrm{~g} / 50 \mathrm{~mL}(p=0.056)$ (Figure 3). 
A

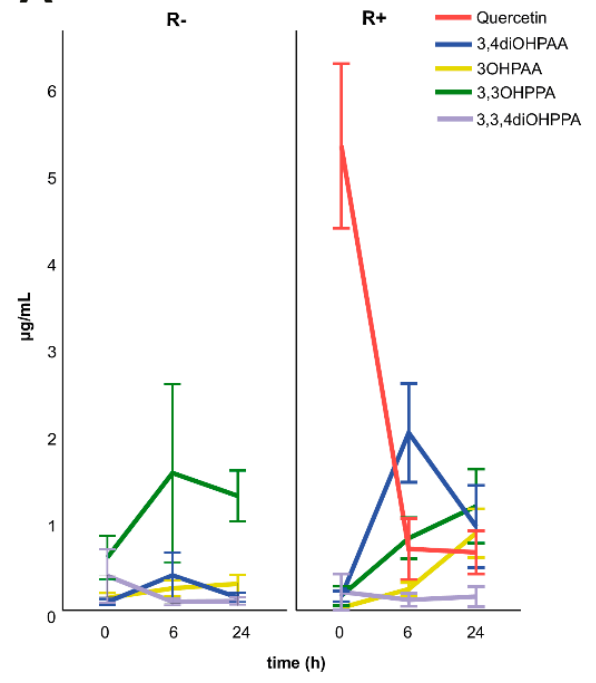

B

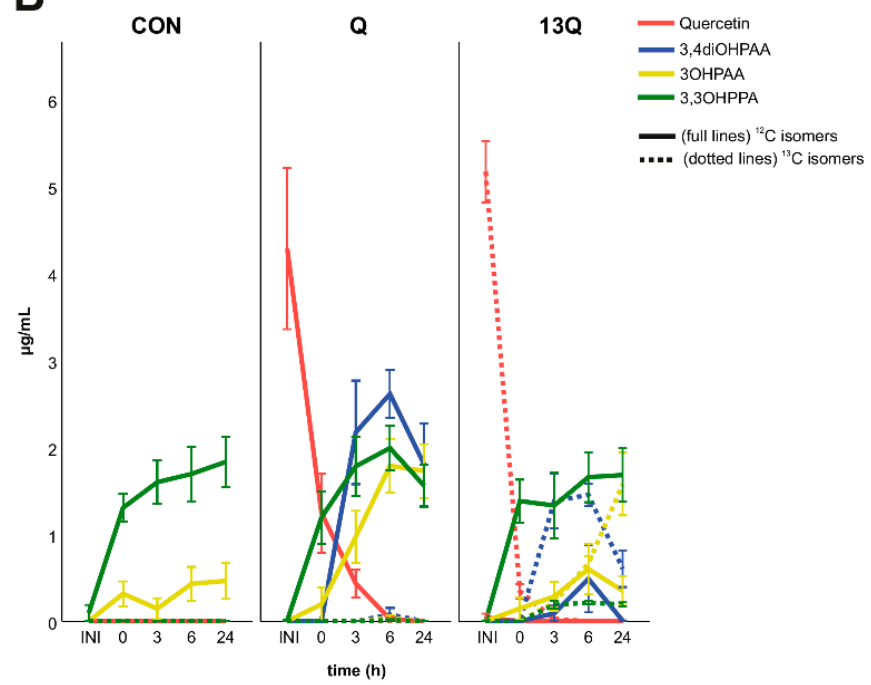

Figure 2. (A) Catabolic products of rutin in fermentations without fibres. $\mathrm{R}+$, fermentation with rutin, $\mathrm{R}-$, corresponding control without rutin; (B) Catabolic products of rutin aglycone-quercetin. CON, without inoculum and quercetin, $\mathrm{Q}$, quercetin, $13 \mathrm{Q},{ }^{13} \mathrm{C}$ all-labelled quercetin isotope. Error bars denote S.E.M., $n=10$ (for A), $\mathrm{n}=4$ (for B). INI, initial concentration added to vials (measured in a parallel sample without faecal inoculum).

R-
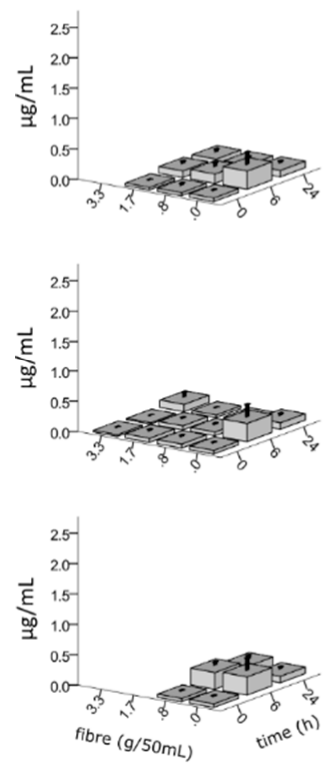

$\mathrm{R}+$
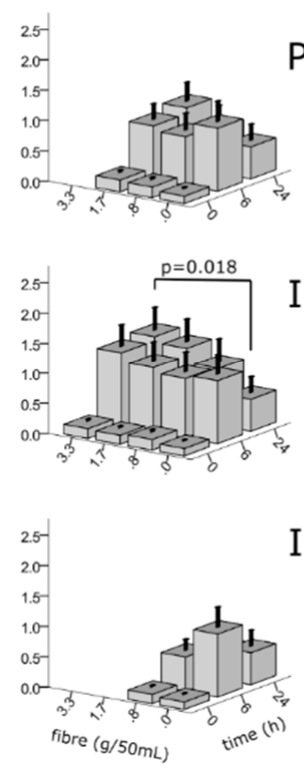

R-

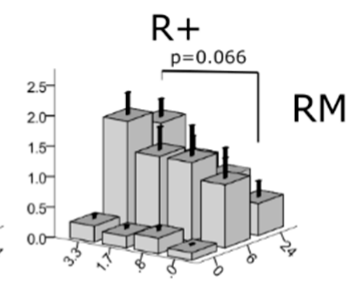

INU
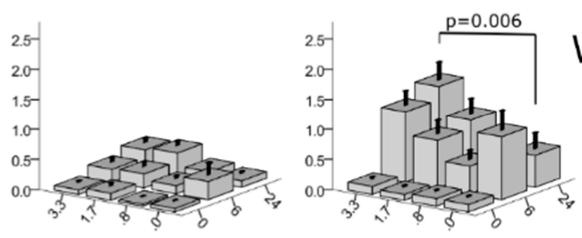

CEL
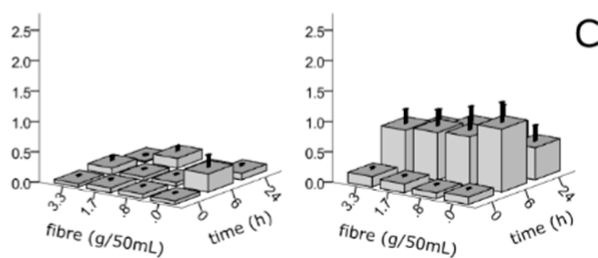

Figure 3. Concentration of 3,4diOHPAA in fermentations in the presence of fibres at four concentrations $(0,0.8,1.7$ and $3.3 \mathrm{~g} / 50 \mathrm{~mL})$ in fermentations with rutin $(\mathrm{R}+; 20 \mu \mathrm{g} / \mathrm{mL})$ and without rutin (R-); INU, inulin, PEC, pectin, ISP, ispaghula, RM, pyrodextrin, WB, wheat bran, CEL, cellulose; means \pm S.E.M; independent samples t-test (2-tailed), $n=10$.

Additionally, there was a 1.6-fold increase for RM at the highest concentration $(p=0.066)$. Plotting the data of individual donors highlighted non-producers of the metabolite (4 of 10), producers ( 6 of 10 subjects, of which donors 1, 2, 3, 4 and 5 or $50 \%$ responded to the addition of fibre with an increased production of 3,4diOHPAA) (Supplementary Materials, Figure S1). The same t-test applied to $\mathrm{AUC}_{24}$ data was not significant for any fibre, however the trend for $\mathrm{AUC}_{24}$ was similar (Figure 4). 


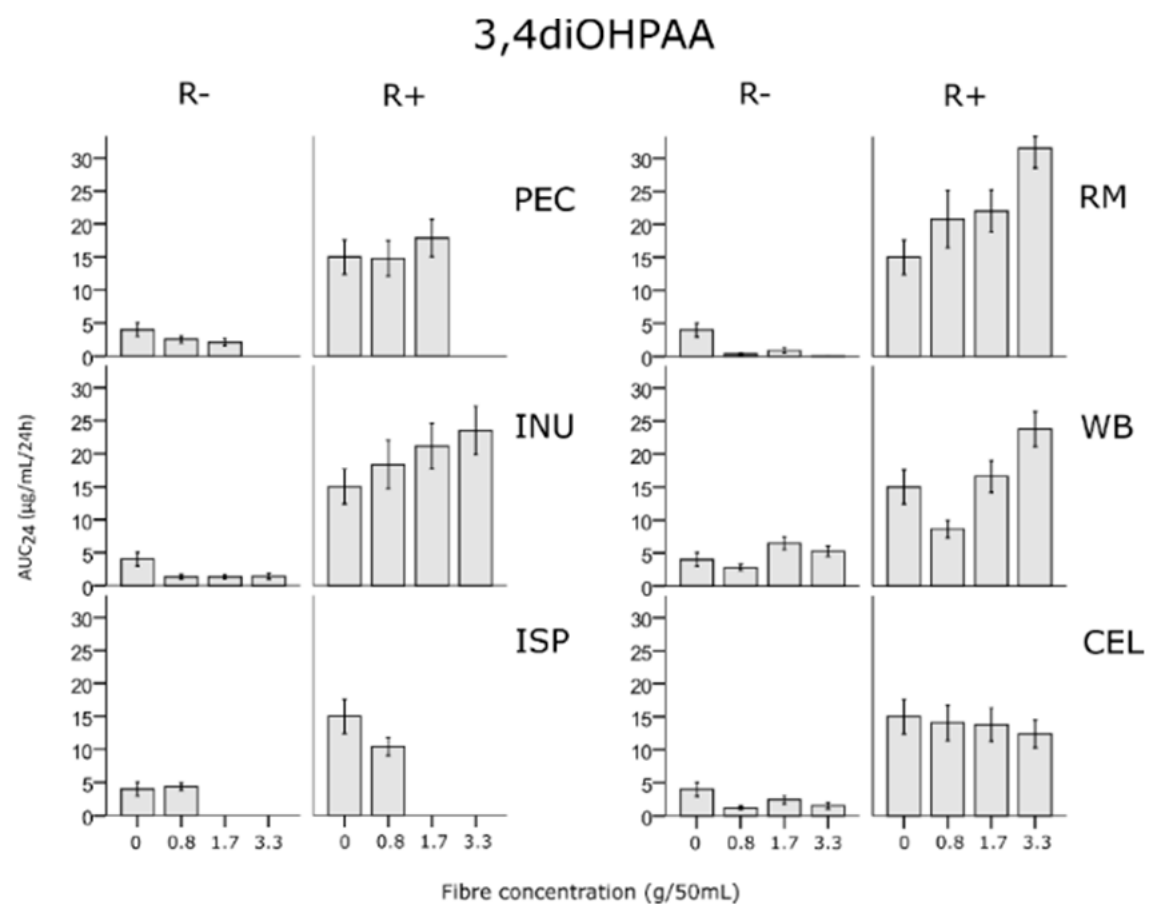

Figure 4. Area under the curve over $24 \mathrm{~h}$ of main metabolite 3,4diOHPAA in fermentations with rutin added $(\mathrm{R}+, 20 \mu \mathrm{g} / \mathrm{mL})$ and without rutin ( $\mathrm{R}-)$ as influenced by presence of fibre at four concentrations $(0,0.8,1.7$ and $3.3 \mathrm{~g} / 50 \mathrm{~mL})$; INU, inulin, PEC, pectin, ISP, psyllium, RM, pyrodextrin, $\mathrm{WB}$, wheat bran, CEL, cellulose; means \pm S.E.M.

\subsection{Impact of Fibres and Rutin on $\mathrm{pH}$ and SCFA Production}

The addition of rutin had a small influence on $\mathrm{pH}$ and SCFA profiles and this effect was fibre-specific. In order to provide a generalised and clear message of the influence of fibre in fermentations with the presence of absence of rutin, we carried out an independent samples t-test on $\mathrm{AUC}_{24}$ values for SCFA across all fibres and concentrations. The presence of rutin clearly increased propionic acid by $19 \%(p<0.001)$, decreased isobutyric acid from $92.4 \mathrm{mmol} / \mathrm{L} / 24 \mathrm{~h}$ to $3.8 \mathrm{mmol} / \mathrm{L} / 24 \mathrm{~h}(p<0.001)$, increased butyric acid by $12 \%(p=0.032)$, valeric acid by $21 \%(p<0.001)$ and caproic acid by $44 \%$ $(p=0.005)$, for full results, see Table 2.

Table 2. Effect of rutin on short chain fatty acid profile expressed as $\mathrm{AUC}_{24}$ irrespective of concentrations and type of fibre (ISP at concentration $0.8 \mathrm{~g} / 50 \mathrm{~mL}, \mathrm{PEC}$ at 0.8 and $1.7 \mathrm{~g} / 50 \mathrm{~mL}, \mathrm{CEL}, \mathrm{INU}, \mathrm{RM}$ at 0.8 , 1.7 and $3.3 \mathrm{~g} / 50 \mathrm{~mL})$.

\begin{tabular}{|c|c|c|c|c|}
\hline \multirow{2}{*}{$\mathrm{AUC}_{24}$} & Rutin not Added & Rutin Added & \multirow{2}{*}{$p$-Value } & \multirow{2}{*}{$n$ (Total) } \\
\hline & Mean \pm S.D. & Mean \pm S.D. & & \\
\hline $\mathrm{pH}$ & $147.11 \pm 19.42$ & $148.68 \pm 19.59$ & 0.187 & 300 \\
\hline $\mathrm{C} 2$ & $617.79 \pm 351.04$ & $618.37 \pm 348.00$ & 0.980 & 300 \\
\hline C3 & $120.48 \pm 66.61$ & $143.05 \pm 88.11$ & 0.000 & 300 \\
\hline IC4 & $92.24 \pm 344.67$ & $3.83 \pm 3.83$ & 0.000 & 300 \\
\hline $\mathrm{C} 4$ & $202.45 \pm 167.81$ & $226.58 \pm 177.94$ & 0.032 & 300 \\
\hline IC5 & $6.80 \pm 6.57$ & $6.87 \pm 6.45$ & 0.874 & 300 \\
\hline $\mathrm{C} 5$ & $11.80 \pm 8.15$ & $14.35 \pm 8.22$ & 0.000 & 300 \\
\hline IC6 & $0.01 \pm 0.13$ & $0.01 \pm 0.11$ & 0.574 & 300 \\
\hline C6 & $2.50 \pm 5.21$ & $3.61 \pm 6.64$ & 0.005 & 300 \\
\hline $\mathrm{C} 7$ & $0.12 \pm 0.62$ & $0.16 \pm 0.67$ & 0.361 & 300 \\
\hline Sum C2-C5 & $1051.56 \pm 578.89$ & $1013.04 \pm 516.17$ & 0.285 & 300 \\
\hline
\end{tabular}

Independent samples t-test (2-tailed) was used. For abbreviations and $\mathrm{AUC}_{24}$ explained, see Materials and methods section. Values except $\mathrm{pH}$ are expressed in $\mathrm{mmol} / \mathrm{L} / 24 \mathrm{~h}$. Statistically significant values $(p<0.05)$ are in bold. 
The effect of rutin presence on SCFA fermentation profiles can be demonstrated in the case of INU (Figure 5). Rutin presence increased $\mathrm{pH}$ at timepoint $6 \mathrm{~h}$ (for $0.8 \mathrm{~g} / 50 \mathrm{~mL}$ the $\mathrm{pH}$ changed from $\mathrm{pH} 4.94$ to $\mathrm{pH} 5.63(p=0.010)$ and a similar, though not significant effect, was seen for other fibre concentrations.

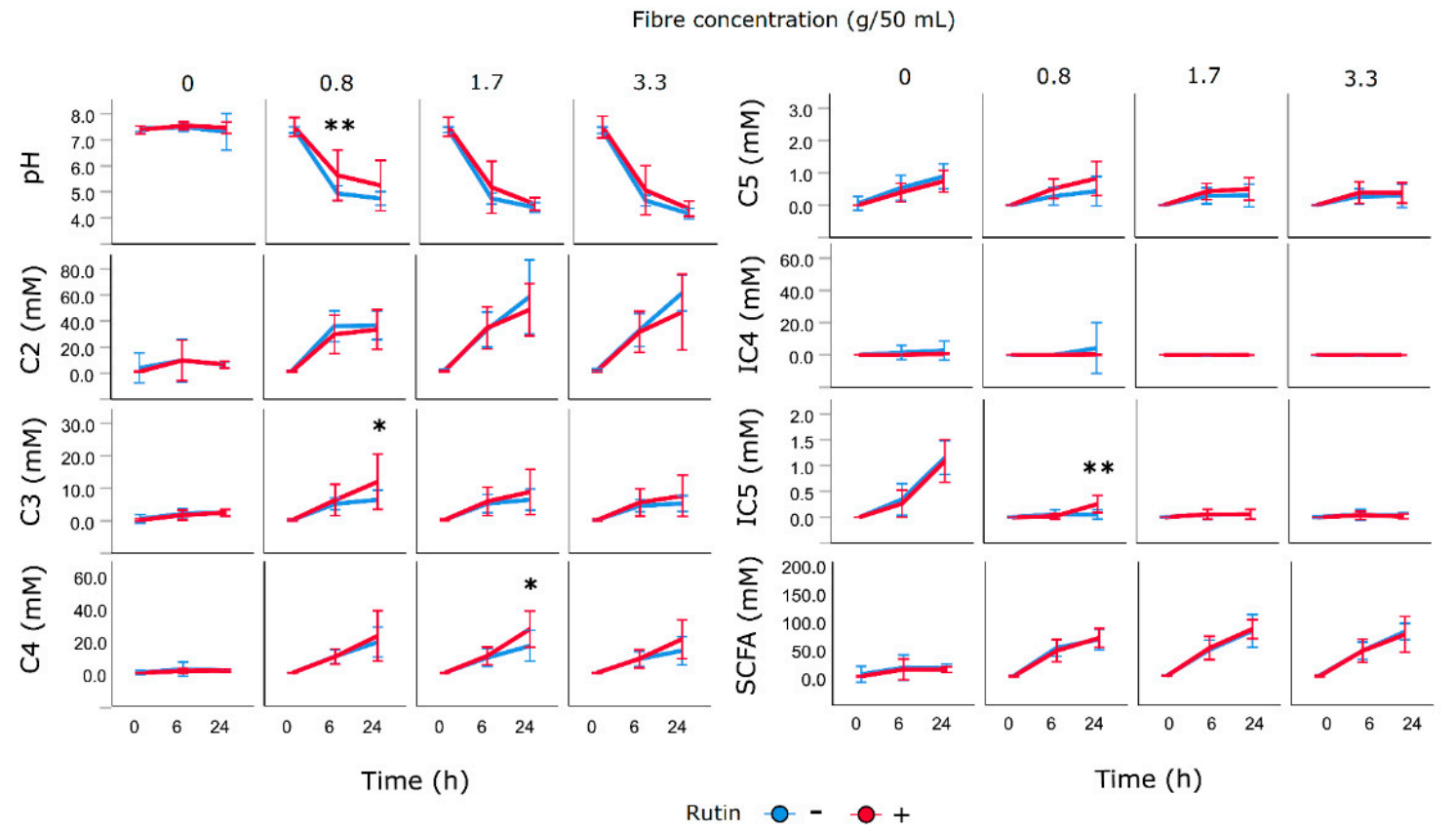

Figure 5. Effect of rutin on formation short chain fatty acid from inulin (3 concentrations) in faecal incubations; * significantly different $(p<0.05),{ }^{* *}(p<0.01)$ between fermentation with rutin (red) and without rutin (blue) using independent samples t-test, adjusted for multiple comparisons, means \pm SD for $n=10$; C2, acetic acid, C3, propionic acid, C4, butyric acid, IC4, isobutyric acid, C5, valeric acid, IC5, isovaleric acid.

There was no effect on acetic acid, but propionic acid was increased significantly at $24 \mathrm{~h}$ for the lowest fibre concentration from 6.47 to $12.01 \mathrm{mmol} / \mathrm{L}(p=0.032)$, again, with a similar though not significant effect for both higher fibre concentrations. Rutin also caused an increase of butyric acid at $24 \mathrm{~h}$, from 16.86 to $27.20 \mathrm{mmol} / \mathrm{L},(p=0.020)$ and isovaleric acid at $24 \mathrm{~h}$ from 0.056 to $0.251 \mathrm{mmol} / \mathrm{L}$, $(p=0.036)$. In contrast, in the presence of ISP, addition of rutin caused a decrease of acetic acid at $24 \mathrm{~h}$ from 23.99 to $36.20 \mathrm{mmol} / \mathrm{L}(p=0.034)$, increase of propionic acid from 16.26 to $11.63 \mathrm{mmol} / \mathrm{L}$ $(p=0.044)$ and decrease of valeric acid at $24 \mathrm{~h}$ from 1.11 to $0.78 \mathrm{mmol} / \mathrm{L}(p=0.026)$. Taken together, the data show that rutin slows down the fermentation of fermentable fibres and shifts the SCFA pattern towards production of propionic acid and branched short chain fatty acids. Full data on the effect of rutin on SCFA production of all fibres can be found in Supplementary Materials, Figure S2.

\section{Discussion}

This study aimed to determine if the catabolism of rutin to phenolic acids by the gut microbiota is affected by dietary fibre, We have shown that the type of dietary fibre alters the pattern of rutin catabolism in an in vitro gut fermentation model. Inulin, WB and RM significantly increased the concentrations of the main rutin metabolite, 3,4diOHPAA at $24 \mathrm{~h}$. This may have important consequences on the bioavailability of 3,4diOHPAA and its biological activity. 3,4diOHPAA was previously shown to have a broad spectrum of potentially beneficial activities for mucosal health $[15,26,43]$ and cardiometabolic outcomes [27]. The effect of fibre on phenolic acid production was confirmed using ${ }^{13} \mathrm{C}$ isotopically labelled quercetin. Three possible mechanisms of action for this interaction between the fibre and rutin catabolism are proposed: (i) sequestration by some fibres, (ii) changes in microbial communities driven by either substrate availability or antimicrobial action of released 
phenolics and (iii) saturation/competitive inhibition of microbial enzymes by fibres or their associated phenolic metabolites.

Spiking with a standard compound mixture revealed selective sequestration of (poly)phenolics by some fibres. Quercetin recovery was significantly reduced in the presence of ISP and WB. The phenolic acids were selectively complexed by $\mathrm{WB}$, those with two $-\mathrm{OH}$ substitutions of the benzene ring showed a higher affinity than those with one. Methylation reduced the affinity to WB (as seen for ferulic and caffeic acid) while reduction of the side chain increased the affinity (3,3,4diOHPPA vs. caffeic acid). Polyphenol binding capacity thus depends on their molecular weight, conformational mobility and flexibility, water solubility, and joint effects of these three factors [44]. Branched complex polysaccharides offer additional binding sites and together with the degree of the polyphenol B-ring substitution can play a major role in the extent of binding interactions. The high sequestration capacity of WB has been demonstrated for other organic compounds such as bile acids [45] and carcinogens [40]. Complex polysaccharides such as WB [46] and those that form viscous solutions (e.g., PEC) offer additional hydrophobic pockets sequestrating proanthocyanidins in comparison to filamentous or globular polysaccharides (xyloglucan or cellulose) [47].

It is well established that different fibres can selectively promote the populations and activities of individual bacterial species. and previous in vitro studies have suggested that the presence of glucose increases phenolic acid production from quercetin in fermentations $[15,19]$, which is likely to be via its effect on the microbial catabolism or composition. We did not measure bacterial populations in this study but in studies by others, $16 \mathrm{~S}$ rDNA profiling has previously that the static batch incubation model is useful to mimic colon microbial processes and is widely used to assess the impact of dietary factors on bacterial metabolism in a reproducible fashion for high throughput studies [48]. The abundance of lactobacilli increased in the presence of xylo-oligosaccharides and INU when compared to control without fibre or to the microcrystalline CEL, while resistant starch increased the Bacteroidaecae family. Moreover, in that study, these fibres decreased the relative abundance of the Lachnospiraceae family [48]. Inulin has a demonstrated effect on the growth of bifidobacteria both in vitro [49] and in vivo [50-52], highlighting the relevance of batch incubations for initial screening purposes. In another in vitro study, dietary fibres caused specific changes: resistant starch caused a 6-13-fold increase in abundance of Ruminococcus bromii and increased the abundance of several species of bifidobacteria. PEC increased bifidobacteria and F. prausnitzii, while INU increased Anaerostipes hadrus and Coprococcus. eutactus; arabinoxylans, which presumably represent the highest fibre fraction of our WB sample increased the abundance of bifidobacteria, mainly of Bifidobacterum bifidum and B. longum up to 13-times [53].

Changes in microbial profile may play crucial role in phenolic catabolic profile. Microbial strains capable of complete catabolic breakdown of rutin to phloroglucinol, carbon dioxide, 3,4-dihydroxybenzaldehyde and 3,4diOHPAA include Butyrivibrio sp., lactobacilli and some other strains [54]. Clostridium perfringens, Bacteroides fragilis [55] Eubacterium ramulus and Flavonifractor plautii showed the ability to produce 3,4diOHPAA from quercetin [55]. Lactobacilli such as Lactobacillus brevis, L. fermentum and L. plantarum metabolize phenolic acids by decarboxylation and/or reduction, yielding dihydroderivatives or corresponding aldehydes [56]. L. fermentum was shown to reduce caffeic acid to dihydrocaffeic acid and similarly $p$-coumaric acid is metabolised by other Lactobacillus spp. [ 57,58$]$. Changes in abundance of these species and possibly many others, triggered by the presence of fibre, is likely to be responsible for the effect of dietary fibres on rutin catabolism seen in our study. The interplay between fibres, polyphenols and microbiota is very complex. Polyphenols are catabolised in the colon by specific microbial species, they $\mathrm{n}$ turn shape gut microbiota composition. This phenomenon has been recently reviewed $[59,60]$.

Evidence from animal models has shown that pectin interacts with polyphenols in an as yet unknown way and that administration in combination (apple polyphenol fraction + fibre fraction) was more effective in preventing atherosclerosis in a mouse model than apple polyphenol fraction or fibre fraction only [61] or that plasma levels of quercetin are higher in rats fed a rutin-pectin-diet than on a rutin-cellulose diet or basal diet with rutin $[62,63]$. 
Very few studies have investigated the fate of rutin or quercetin at physiological concentrations, $[14,30]$ with other studies considering doses achievable only by supplements [15]. Our results differ from studies using higher doses of the parent compounds in that they report slower deglycosylation, [13] or observe 3,4diOHBA, 3,3OHPPA and 3,3,4diOHPPA and other metabolites alongside the four metabolites observed in the present study $[13,15,64]$. Studies with high doses also report higher recoveries of total metabolites to initial quercetin and longer lag time in decomposition of the parent compound, which may be due to saturation of microbial hydrolases and slower release of the aglycone or growth inhibition of selected intestinal bacterial species [65].

In our study, almost all initial rutin aglycone was degraded during the first $6 \mathrm{~h}$, whereas in another study, most of the rutin $(336 \mu \mathrm{g} / \mathrm{mL})$ was still intact after $6 \mathrm{~h}$ fermentation [15]. This probably reflects the fact that in our study, the rutin dose was much lower, close to physiological intake. The fibres used here were themselves a good source of phenolic acids probably related to the non-extractable polyphenols. Phenolic precursors of these metabolites are an inevitable component of cell wall structures, bridging and cross-linking structural carbohydrate polymers and may differ among plants [46].

Fibre intake in clinical trials is linked to the presence of phenolic metabolites in stool, such as ferulic acid, 3,4OH3MPPA and 3OHPPA [66]. These aromatic compounds can also derive from the phenylalanine, tyrosine and tryptophan degradation [67] forming in particular, PAA, 4OHPAA and indole-3-acetic acid [68]. These catabolic pathways exist in parallel and interact, suggesting a considerable role of the food matrix in polyphenol metabolism. For example, ferulic acid catabolism to 3OHPAA and 3,4OHPAA was reduced in vitro in subjects on a high-fat-high protein diet [69].

Our study showed which aromatic acids originated from protein catabolism, such as those occurring in blank-medium only and those present in vials with cellulose (mainly PAA, 3PPA and less 4OHPAA, 3,3OHPPA and 3,4OHPPA, those associated with the fibre and probably originating from plant-derived phenylpropanoids and amino acids (Figure 2). The presence of specific metabolites such as phenyllactic acid in INU fermentations is of interest and suggesting a specific precursor in the fibre. The 3-Phenyllactic acid is a potent antimicrobial agent used in the cheese industry and is produced by several strains of lactic acid bacteria, such as human colonic L. rhamnosus, from phenylalanine [70]. It promotes growth of some bacterial groups [71] and may act in quorum sensing [72,73]. The presence of this metabolite could contribute to the prebiotic effect of inulin.

The presence of pectin led to production of 3,3OH4MPPA and 3,3OHPPA while WB was associated with high abundance of PAA and 3,3OHPPA, but also contained ferulic acid and 3,4OH3MPPA (Table 1, Figure 2). This suggests different structural properties or different precursors. Interestingly, $m$-hydroxy dihydro-catabolites of rutin could be more resistant to further catabolism as microbial enzymes show preference towards faster removal of the hydroxyl or O-methoxy group in the para-position [74], explaining their higher proportion.

The addition of rutin influences carbohydrate fermentation. Fermentation of fibres to SCFA is inhibited by rutin and the branched chain fatty acids increase in response to this, possibly originating from non-carbohydrate sources. Except for RM, rutin slightly increased $\mathrm{pH}$ in fermentations of all fibres including CEL, suggesting a slight effect on carbohydrate metabolism or microbiota profile even at the low, physiologically relevant concentrations used. Polyphenols have been shown to have potential to alter gut microecology by a prebiotic-like effect; selectively inhibiting the growth of certain bacterial species [65]. Isobutyric acid, for instance is produced by Odoribacter sp. [75] so such marked decrease may denote an effect on this or a similar microbial species.

\section{Conclusions}

In this study, dietary fibres showed differential interactions with dietary rutin which affected the pattern of phenolic acid and SCFA production. Wheat bran, pectin, psyllium, resistant maltodextrin, but not cellulose, were a rich source of phenolic acids producing a profile with some unique metabolites, characteristic for each fibre. Rutin at the physiological dose tested was catabolised to four main phenolic acids. Addition of inulin, an analogue to $20 \mathrm{~g}$ bolus dietary intake increased the concentration 
of the main bioactive metabolite, 3,4diOHPAA in fermentations at $24 \mathrm{~h} \mathrm{2.3-fold} \mathrm{and} \mathrm{addition} \mathrm{of}$ wheat bran 2.5-fold. Moreover, the area under the curve of this metabolite tended to be higher in fermentations with fibre, suggesting higher bioaccessibility. Understanding these interactions is essential as fibre and polyphenols are often eaten together and the phenolic acids and SCFA produced may be important effectors for key health benefits. In vitro fermentation models have some limitations in closely modelling events in the human colon as they do not mimic absorption of bacterial products but they are useful for predicting microbial activity. The interactions between fibre, polyphenols and the gut microbiota need to be further studied in vivo.

Supplementary Materials: The following are available online at http://www.mdpi.com/2072-6643/12/6/1577/s1, Table S1: Overview of the chemicals used in the study with their abbreviations Table S2: Basic method validation and GC-MS of the TMS derivatives of phenolic metabolites in batch incubations after spiking the sample with two concentrations of standards, Table S3: Recoveries of metabolites $(\mu \mathrm{g} / \mathrm{mL})$ spiked with $5 \mu \mathrm{g} / \mathrm{mL}$ of standard into aqueous suspensions of fibres (concentration equals that used in test) with an aim to investigate fibre sequestration properties, Figure S1: Inter-individual differences in the production of 3,4diOHPAA from rutin among donors and response to the presence of fibres, Figure S2: Effect of rutin on formation of short chain fatty acid from fibres ( 3 concentrations) in faecal incubations, Figure S3: Information sheet on the low polyphenol diet provided the stool donors.

Author Contributions: Conceptualization, C.A.E. and E.C.; methodology, C.A.E., J.H., E.C. and D.J.M.; software, J.H.; validation, C.A.E.; formal analysis, T.P. and W.M.; investigation, J.H., V.M., A.G. and M.H.; resources, C.A.E.; data curation, C.A.E.; writing-original draft preparation, J.H.; writing-review and editing, C.A.E., E.C. and D.J.M.; visualization, J.H.; supervision, C.A.E., T.P., W.M., D.J.M. and E.C.; project administration, C.A.E.; funding acquisition, C.A.E. All authors have read and agreed to the published version of the manuscript.

Funding: This research was funded by the BBSRC (BB/M027724/1).

Conflicts of Interest: The authors declare no conflict of interest.

\section{References}

1. Pérez-Jiménez, J.; Fezeu, L.; Touvier, M.; Arnault, N.; Manach, C.; Hercberg, S.; Galan, P.; Scalbert, A. Dietary intake of 337 polyphenols in French adults. Am. J. Clin. Nutr. 2011, 93, 1220-1228. [CrossRef] [PubMed]

2. Brat, P.; Georgé, S.; Bellamy, A.; Du Chaffaut, L.; Scalbert, A.; Mennen, L.; Arnault, N.; Amiot, M.J. Daily polyphenol intake in France from fruit and vegetables. J. Nutr. 2006, 136, 2368-2373. [CrossRef] [PubMed]

3. Williamson, G.; Manach, C. Bioavailability and bioefficacy of polyphenols in humans. II. Review of 93 intervention studies. Am. J. Clin. Nutr. 2005, 81, 243S-255S. [CrossRef] [PubMed]

4. Neuhouser, M.L. Review: Dietary flavonoids and cancer risk: Evidence from human population studies. Nutr. Cancer 2004, 50, 1-7. [CrossRef]

5. Ovaskainen, M.-L.; Törrönen, R.; Koponen, J.M.; Sinkko, H.; Hellström, J.; Reinivuo, H.; Mattila, P. Dietary intake and major food sources of polyphenols in Finnish adults. J. Nutr. 2008, 138, 562-566. [CrossRef] [PubMed]

6. Zamora-Ros, R.; Andres-Lacueva, C.; Lamuela-Raventós, R.M.; Berenguer, T.; Jakszyn, P.; Barricarte, A.; Ardanaz, E.; Amiano, P.; Dorronsoro, M.; Larrañaga, N. Estimation of dietary sources and flavonoid intake in a Spanish adult population (EPIC-Spain). J. Am. Diet Assoc. 2010, 110, 390-398. [CrossRef] [PubMed]

7. Neveu, V.; Perez-Jiménez, J.; Vos, F.; Crespy, V.; du Chaffaut, L.; Mennen, L.; Knox, C.; Eisner, R.; Cruz, R.; Wishart, D.; et al. Phenol-Explorer: An online comprehensive database on polyphenol contents in foods. Database 2010. [CrossRef] [PubMed]

8. Wada, L.; Ou, B. Antioxidant activity and phenolic content of Oregon caneberries. J. Agric. Food Chem. 2002, 50, 3495-3500. [CrossRef]

9. Hui, C.; Qi, X.; Qianyong, Z.; Xiaoli, P.; Jundong, Z.; Mantian, M. Flavonoids, flavonoid subclasses and breast cancer risk: A meta-analysis of epidemiologic studies. PLoS ONE 2013, 8, e54318. [CrossRef]

10. Edwards, R.L.; Lyon, T.; Litwin, S.E.; Rabovsky, A.; Symons, J.D.; Jalili, T. Quercetin reduces blood pressure in hypertensive subjects. J. Nutr. 2007, 137, 2405-2411. [CrossRef]

11. Wang, X.; Ouyang, Y.Y.; Liu, J.; Zhao, G. Flavonoid intake and risk of CVD: A systematic review and meta-analysis of prospective cohort studies. Br. J. Nutr. 2014, 111, 1-11. [CrossRef] [PubMed] 
12. Menezes, R.; Rodriguez-Mateos, A.; Kaltsatou, A.; González-Sarrías, A.; Greyling, A.; Giannaki, C.; Andres-Lacueva, C.; Milenkovic, D.; Gibney, E.; Dumont, J. Impact of flavonols on cardiometabolic biomarkers: A meta-analysis of randomized controlled human trials to explore the role of inter-individual variability. Nutrients 2017, 9, 117. [CrossRef] [PubMed]

13. Rechner, A.R.; Smith, M.A.; Kuhnle, G.; Gibson, G.R.; Debnam, E.S.; Srai, S.K.S.; Moore, K.P.; Rice-Evans, C.A. Colonic metabolism of dietary polyphenols: Influence of structure on microbial fermentation products. Free Radic. Biol. Med. 2004, 36, 212-225. [CrossRef] [PubMed]

14. Aura, A.-M.; O'leary, K.; Williamson, G.; Ojala, M.; Bailey, M.; Puupponen-Pimiä, R.; Nuutila, A.; Oksman-Caldentey, K.-M.; Poutanen, K. Quercetin derivatives are deconjugated and converted to hydroxyphenylacetic acids but not methylated by human fecal flora in vitro. J. Agric. Food Chem. 2002, 50, 1725-1730. [CrossRef] [PubMed]

15. Jaganath, I.B.; Mullen, W.; Lean, M.E.; Edwards, C.A.; Crozier, A. In vitro catabolism of rutin by human fecal bacteria and the antioxidant capacity of its catabolites. Free Radic. Biol. Med. 2009, 47, 1180-1189. [CrossRef] [PubMed]

16. Manach, C.; Morand, C.; Demigné, C.; Texier, O.; Régérat, F.; Rémésy, C. Bioavailability of rutin and quercetin in rats. FEBS Lett. 1997, 409, 12-16. [CrossRef]

17. Baba, S.; Furuta, T.; Fujioka, M.; Goromaru, T. Studies on drug metabolism by use of isotopes XXVII: Urinary metabolites of rutin in rats and the role of intestinal microflora in the metabolism of rutin. J. Pharm. Sci. 1983, 72, 1155-1158. [CrossRef]

18. Griffiths, L.; Barrow, A. Metabolism of flavonoid compounds in germ-free rats. Biochem. J. 1972, 130, 1161-1162. [CrossRef]

19. Jaganath, I.B.; Jaganath, I.B.; Mullen, W.; Edwards, C.A.; Crozier, A. The relative contribution of the small and large intestine to the absorption and metabolism of rutin in man. Free Radic. Res. 2006, 40, 1035-1046. [CrossRef]

20. Hollman, P.C.; Gaag, M.V.; Mengelers, M.J.; Van Trijp, J.M.; De Vries, J.H.; Katan, M.B. Absorption and disposition kinetics of the dietary antioxidant quercetin in man. Free Radic. Biol. Med. 1996, 21, 703-707. [CrossRef]

21. Alkhaldy, A.; Edwards, C.A.; Combet, E. The urinary phenolic acid profile varies between younger and older adults after a polyphenol-rich meal despite limited differences in in vitro colonic catabolism. Eur. J. Nutr. 2019, 58, 1095-1111. [CrossRef] [PubMed]

22. Alkhaldy, A.; Edwards, A.C.; Combet, E. Effect of ethnicity and a fermentable fibre on the in vitro colonic metabolism of polyphenols. Proc. Nutr. Soc. 2012, 71, E61. [CrossRef]

23. Vlassopoulos, A.; Lean, M.E.J.; Combet, E. Role of oxidative stress in physiological albumin glycation: A neglected interaction. Free Radic. Biol. Med. 2013, 60, 318-324. [CrossRef] [PubMed]

24. Tang, Y.; Nakashima, S.; Saiki, S.; Myoi, Y.; Abe, N.; Kuwazuru, S.; Zhu, B.; Ashida, H.; Murata, Y.; Nakamura, Y. 3,4-Dihydroxyphenylacetic acid is a predominant biologically-active catabolite of quercetin glycosides. Food Res. Int. 2016, 89, 716-723. [CrossRef] [PubMed]

25. Rechner, A.R.; Kroner, C. Anthocyanins and colonic metabolites of dietary polyphenols inhibit platelet function. Thromb. Res. 2005, 116, 327-334. [CrossRef]

26. Monagas, M.; Khan, N.; Andrés-Lacueva, C.; Urpí-Sardá, M.; Vázquez-Agell, M.; Lamuela-Raventós, R.M.; Estruch, R. Dihydroxylated phenolic acids derived from microbial metabolism reduce lipopolysaccharidestimulated cytokine secretion by human peripheral blood mononuclear cells. Br. J. Nutr. 2009, 102, 201-206. [CrossRef]

27. Pashikanti, S.; de Alba, D.R.; Boissonneault, G.A.; Cervantes-Laurean, D. Rutin metabolites: Novel inhibitors of nonoxidative advanced glycation end products. Free Radic. Biol. Med. 2010, 48, 656-663. [CrossRef]

28. Sánchez-Patán, F.; Cueva, C.; Monagas, M.; Walton, G.E.; Gibson, G.R.; Martín-Álvarez, P.J.; Moreno-Arribas, M.V.; Bartolomé, B. Gut microbial catabolism of grape seed flavan-3-ols by human faecal microbiota. Targetted analysis of precursor compounds, intermediate metabolites and end-products. Food Chem. 2012, 131, 337-347. [CrossRef]

29. Jarosova, V.; Vesely, O.; Marsik, P.; Jaimes, J.D.; Smejkal, K.; Kloucek, P.; Havlik, J. Metabolism of stilbenoids by human faecal microbiota. Molecules 2019, 24, 1155. [CrossRef] [PubMed]

30. Parkar, S.G.; Trower, T.M.; Stevenson, D.E. Fecal microbial metabolism of polyphenols and its effects on human gut microbiota. Anaerobe 2013, 23, 12-19. [CrossRef] 
31. Mansoorian, B.; Combet, E.; Alkhaldy, A.; Garcia, A.L.; Edwards, C.A. Impact of fermentable fibres on the colonic microbiota metabolism of dietary polyphenols rutin and quercetin. Int. J. Environ. Res. Pubic. Health 2019, 16, 292. [CrossRef] [PubMed]

32. Koziolek, M.; Grimm, M.; Becker, D.; Iordanov, V.; Zou, H.; Shimizu, J.; Wanke, C.; Garbacz, G.; Weitschies, W. Investigation of $\mathrm{pH}$ and temperature profiles in the GI tract of fasted human subjects using the Intellicap ${ }^{\circledR}$ system. J. Pharm. Sci. 2015, 104, 2855-2863. [CrossRef] [PubMed]

33. Walker, A.W.; Duncan, S.H.; Leitch, E.C.M.; Child, M.W.; Flint, H.J. pH and peptide supply can radically alter bacterial populations and short-chain fatty acid ratios within microbial communities from the human colon. Appl. Environ. Microbiol. 2005, 71, 3692-3700. [CrossRef] [PubMed]

34. Crittenden, R.; Karppinen, S.; Ojanen, S.; Tenkanen, M.; Fagerström, R.; Mättö, J.; Saarela, M.; Mattila-Sandholm, T.; Poutanen, K. In vitro fermentation of cereal dietary fibre carbohydrates by probiotic and intestinal bacteria. J. Sci. Food Agric. 2002, 82, 781-789. [CrossRef]

35. Brownlee, I.A. The physiological roles of dietary fibre. Food Hydrocoll. 2011, 25, 238-250. [CrossRef]

36. Bazzocco, S.; Mattila, I.; Guyot, S.; Renard, C.M.; Aura, A.-M. Factors affecting the conversion of apple polyphenols to phenolic acids and fruit matrix to short-chain fatty acids by human faecal microbiota in vitro. Eur. J. Nutr. 2008, 47, 442-452. [CrossRef]

37. Khossousi, A.; Binns, C.; Dhaliwal, S.; Pal, S. The acute effects of psyllium on postprandial lipaemia and thermogenesis in overweight and obese men. Br. J. Nutr. 2008, 99, 1068-1075. [CrossRef]

38. Harris, H.C.; Edwards, C.A.; Morrison, D.J. Impact of glycosidic bond configuration on short chain fatty acid production from model fermentable carbohydrates by the human gut microbiota. Nutrients 2017, 9, 26. [CrossRef]

39. Ladas, S.; Isaacs, P.; Murphy, G.; Sladen, G. Fasting and postprandial ileal function in adapted ileostomates and normal subjects. Gut 1986, 27, 906-912. [CrossRef]

40. Ferguson, L.; Harris, P. Protection against cancer by wheat bran: Role of dietary fibre and phytochemicals. Eur. J. Cancer Prev. 1999, 8, 17-26. [CrossRef]

41. Combet, E.; Lean, M.E.; Boyle, J.G.; Crozier, A.; Davidson, D.F. Dietary flavonols contribute to false-positive elevation of homovanillic acid, a marker of catecholamine-secreting tumors. Clin. Chim. Acta 2011, 412, 165-169. [CrossRef] [PubMed]

42. Grün, C.H.; van Dorsten, F.A.; Jacobs, D.M.; Le Belleguic, M.; van Velzen, E.J.; Bingham, M.O.; Janssen, H.-G.; van Duynhoven, J.P. GC-MS methods for metabolic profiling of microbial fermentation products of dietary polyphenols in human and in vitro intervention studies. J. Chromatogr. B 2008, 871, 212-219. [CrossRef] [PubMed]

43. Kim, D.-H.; Jung, E.-A.; Sohng, I.-S.; Han, J.-A.; Kim, T.-H.; Han, M.J. Intestinal bacterial metabolism of flavonoids and its relation to some biological activities. Arch. Pharm. Res. 1998, 21, 17-23. [CrossRef] [PubMed]

44. Le Bourvellec, C.; Renard, C. Interactions between polyphenols and macromolecules: Quantification methods and mechanisms. Crit. Rev. Food Sci. Nutr. 2012, 52, 213-248. [CrossRef] [PubMed]

45. Vahouny, G.V.; Tombes, R.; Cassidy, M.M.; Kritchevsky, D.; Gallo, L.L. Dietary fibers: V. Binding of bile salts, phospholipids and cholesterol from mixed micelles by bile acid sequestrants and dietary fibers. Lipids 1980, 15, 1012-1018. [CrossRef] [PubMed]

46. Carpita, N.C.; Gibeaut, D.M. Structural models of primary cell walls in flowering plants: Consistency of molecular structure with the physical properties of the walls during growth. Plant J. 1993, 3, 1-30. [CrossRef] [PubMed]

47. Le Bourvellec, C.; Bouchet, B.; Renard, C. Non-covalent interaction between procyanidins and apple cell wall material. Part III: Study on model polysaccharides. Biophys. Acta Gen. Subj. 2005, 1725, 10-18. [CrossRef] [PubMed]

48. Tsitko, I.; Wiik-Miettinen, F.; Mattila, O.; Rosa-Sibakov, N.; Seppänen-Laakso, T.; Maukonen, J.; Nordlund, E.; Saarela, M. A small in vitro fermentation model for screening the gut microbiota effects of different fiber preparations. Int. J. Mol. Sci. 2019, 20, 1925. [CrossRef]

49. Roberfroid, M.B.; Van Loo, J.A.; Gibson, G.R. The bifidogenic nature of chicory inulin and its hydrolysis products. J. Nutr. 1998, 128, 11-19. [CrossRef] 
50. Salazar, N.; Dewulf, E.M.; Neyrinck, A.M.; Bindels, L.B.; Cani, P.D.; Mahillon, J.; de Vos, W.M.; Thissen, J.P.; Gueimonde, M.; de Los Reyes-Gavilán, C.G.; et al. Inulin-type fructans modulate intestinal Bifidobacterium species populations and decrease fecal short-chain fatty acids in obese women. Clin. Nutr. 2015, 34, 501-507. [CrossRef]

51. Lohner, S.; Jakobik, V.; Mihályi, K.; Soldi, S.; Vasileiadis, S.; Theis, S.; Sailer, M.; Sieland, C.; Berényi, K.; Boehm, G.; et al. Inulin-type fructan supplementation of 3-to 6-year-old children is associated with higher fecal Bifidobacterium concentrations and fewer febrile episodes requiring medical attention. J. Nutr. 2018, 148, 1300-1308. [CrossRef] [PubMed]

52. Reimer, R.A.; Soto-Vaca, A.; Nicolucci, A.C.; Mayengbam, S.; Park, H.; Madsen, K.L.; Menon, R.; Vaughan, E.E. Effect of chicory inulin-type fructan-containing snack bars on the human gut microbiota in low dietary fiber consumers in a randomized crossover trial. Am. J. Clin. Nutr. 2020. [CrossRef] [PubMed]

53. Reichardt, N.; Vollmer, M.; Holtrop, G.; Farquharson, F.M.; Wefers, D.; Bunzel, M.; Duncan, S.H.; Drew, J.E.; Williams, L.M.; Milligan, G.; et al. Specific substrate-driven changes in human faecal microbiota composition contrast with functional redundancy in short-chain fatty acid production. ISME J. 2018, 12, 610-622. [CrossRef] [PubMed]

54. Blaut, M.; Schoefer, L.; Braune, A. Transformation of flavonoids by intestinal microorganisms. Int. J. Vitam. Nutr. Res. 2003, 73, 79-87. [CrossRef] [PubMed]

55. Ulbrich, K.; Reichardt, N.; Braune, A.; Kroh, L.W.; Blaut, M.; Rohn, S. The microbial degradation of onion flavonol glucosides and their roasting products by the human gut bacteria Eubacterium ramulus and Flavonifractor plautii. Food Res. Int. 2015, 67, 349-355. [CrossRef]

56. Sánchez-Maldonado, A.F.; Schieber, A.; Gänzle, M.G. Structure-function relationships of the antibacterial activity of phenolic acids and their metabolism by lactic acid bacteria. J. Appl. Microbiol. 2011, 111, 1176-1184. [CrossRef]

57. Van Beek, S.; Priest, F.G. Decarboxylation of substituted cinnamic acids by lactic acid bacteria isolated during malt whisky fermentation. Appl. Environ. Microbiol. 2000, 66, 5322-5328. [CrossRef] [PubMed]

58. Rodriguez, H.; Landete, J.M.; Curiel, J.A.; de Las Rivas, B.; Mancheño, J.M.; Muñoz, R. Characterization of the p-coumaric acid decarboxylase from Lactobacillus plantarum CECT 748T. J. Agric. Food Chem. 2008, 56, 3068-3072. [CrossRef] [PubMed]

59. Kumar Singh, A.; Cabral, C.; Kumar, R.; Ganguly, R.; Kumar Rana, H.; Gupta, A.; Rosaria Lauro, M.; Carbone, C.; Reis, F.; Pandey, A.K. Beneficial effects of dietary polyphenols on gut microbiota and strategies to improve delivery efficiency. Nutrients 2019, 11, 2216. [CrossRef] [PubMed]

60. Chen, T.; Yang, C.S. Biological fates of tea polyphenols and their interactions with microbiota in the gastrointestinal tract: Implications on health effects. Crit. Rev. Food Sci. Nutr. 2019, 1-19. [CrossRef]

61. Auclair, S.; Silberberg, M.; Gueux, E.; Morand, C.; Mazur, A.; Milenkovic, D.; Scalbert, A. Apple polyphenols and fibers attenuate atherosclerosis in apolipoprotein E-deficient mice. J. Agric. Food Chem. 2008, 56, 5558-5563. [CrossRef] [PubMed]

62. Tamura, M.; Nakagawa, H.; Tsushida, T.; Hirayama, K.; Itoh, K. Effect of pectin enhancement on plasma quercetin and fecal flora in rutin-supplemented mice. J. Food Sci. 2007, 72, S648-S651. [CrossRef] [PubMed]

63. Nishijima, T.; Iwai, K.; Saito, Y.; Takida, Y.; Matsue, H. Chronic ingestion of apple pectin can enhance the absorption of quercetin. J. Agric. Food Chem. 2009, 57, 2583-2587. [CrossRef] [PubMed]

64. Justesen, U.; Arrigoni, E. Electrospray ionisation mass spectrometric study of degradation products of quercetin, quercetin-3-glucoside and quercetin-3-rhamnoglucoside, produced by in vitro fermentation with human faecal flora. Rapid Commun. Mass Spectrom. 2001, 15, 477-483. [CrossRef] [PubMed]

65. Parkar, S.G.; Stevenson, D.E.; Skinner, M.A. The potential influence of fruit polyphenols on colonic microflora and human gut health. Int. J. Food Microbiol. 2008, 124, 295-298. [CrossRef] [PubMed]

66. Russell, W.R.; Gratz, S.W.; Duncan, S.H.; Holtrop, G.; Ince, J.; Scobbie, L.; Duncan, G.; Johnstone, A.M.; Lobley, G.E.; Wallace, R.J. High-protein, reduced-carbohydrate weight-loss diets promote metabolite profiles likely to be detrimental to colonic health. Am. J. Clin. Nutr. 2011, 93, 1062-1072. [CrossRef]

67. Macfarlane, G.T.; Macfarlane, S. Bacteria, colonic fermentation, and gastrointestinal health. J. AOAC Int. 2012, 95, 50-60. [CrossRef]

68. Russell, W.R.; Duncan, S.H.; Scobbie, L.; Duncan, G.; Cantlay, L.; Calder, A.G.; Anderson, S.E.; Flint, H.J. Major phenylpropanoid-derived metabolites in the human gut can arise from microbial fermentation of protein. Mol. Nutr. Food Res. 2013, 57, 523-535. [CrossRef] 
69. Russell, W.R.; Hoyles, L.; Flint, H.J.; Dumas, M.-E. Colonic bacterial metabolites and human health. Curr. Opin. Microbiol. 2013, 16, 246-254. [CrossRef]

70. Valerio, F.; Lavermicocca, P.; Pascale, M.; Visconti, A. Production of phenyllactic acid by lactic acid bacteria: An approach to the selection of strains contributing to food quality and preservation. FEMS Microbiol. Lett. 2004, 233, 289-295. [CrossRef]

71. Kaplan, H.; Hutkins, R.W. Fermentation of fructooligosaccharides by lactic acid bacteria and bifidobacteria. Appl. Environ. Microbiol. 2000, 66, 2682-2684. [CrossRef] [PubMed]

72. Chifiriuc, M.C.; Veronica, L.; Dracea, O.; Ditu, L.-M.; Smarandache, D.; Bucur, M.; Larion, C.; Ramona, C.; Sasarman, E. Drastic attenuation of Pseudomonas aeruginosa pathogenicity in a holoxenic mouse experimental model induced by subinhibitory concentrations of phenyllactic acid (PLA). Int. J. Mol. Sci. 2007, 8, 583-592. [CrossRef]

73. Chifiriuc, M.-C.; Diţu, L.; Banu, O.; Bleotu, C.; Drăcea, O.; Bucur, M.; Larion, C.; Israil, A.M.; Lazăr, V. Subinhibitory concentrations of phenyl lactic acid interfere with the expression of virulence factors in Staphylococcus aureus and Pseudomonas aeruginosa clinical strains. Roum. Arch. Microbiol. Immunol. 2009, 68, 27-33. [PubMed]

74. Williamson, G.; Clifford, M.N. Colonic metabolites of berry polyphenols: The missing link to biological activity? Br. J. Nutr. 2010, 104, S48-S66. [CrossRef]

75. Granado-Serrano, A.B.; Martín-Garí, M.; Sánchez, V.; Solans, M.R.; Berdún, R.; Ludwig, I.A.; Rubió, L.; Vilaprinyó, E.; Portero-Otín, M.; Serrano, J.C.E. Faecal bacterial and short-chain fatty acids signature in hypercholesterolemia. Sci. Rep. 2019, 9, 1772. [CrossRef]

(C) 2020 by the authors. Licensee MDPI, Basel, Switzerland. This article is an open access article distributed under the terms and conditions of the Creative Commons Attribution (CC BY) license (http://creativecommons.org/licenses/by/4.0/). 